\title{
The United States Motivation in Having Cyber Security Cooperation With China
}

\section{Devi Purwanti}

\section{Devi Purwanti}

Affiliation : Andalas Institute of International Studies (ASSIST)

City : Padang

Country : Indonesia

Email

devipurwanti970@gmail.com

\section{History}

$\begin{array}{lll}\text { Submission } & : & \text { 20 June } 2021 \\ \text { Review } & : & \text { 4 Juli } 2021 \\ \text { Completed } & & \\ \text { Accepted } & : & \text { 25 July } 2021 \\ \text { Available } & : & \text { 30 July } 2021 \\ \text { Online } & & \end{array}$

DOI :

10.51413/jisea.Vol2.Iss1.2021.105-122

\section{Copyright}

This is an open access article distributed under the term of the creative commons attribution 4.0 international licence

\begin{abstract}
The United States and China had conducted cyber cooperation since 2011. But in 2013, both states were involved in the cyber conflict that made the previous cyber collaboration had been ineffective. After that, in 2015, both states agreed to re-form cyber cooperation. This study aims to analyse the United States' motivation in conducting cyber partnerships with China using the cybersecurity concept. This research has discovered at the national level, the United States tried to achieve its information assurance through cyber defence strategy by strengthening collaboration. On the other hand, at the international level, norm construction through bilateral collaboration has made the United States become an impactful actor in international cybersecurity.
\end{abstract}

Key Words: Cooperation, the United States, China, Cybersecurity, Norms Construction

\section{Cite this article :}

Purwanti, Devi. "The United States Motivation in Having Cyber Security Cooperation With China." Journal of International Studies on Energy Affairs, 2021. https://doi.org/10.51413/jisea.Vol2.Iss1.2021.105-122.
- Journal of Intenational Studies JISEA A 


\section{INTRODUCTION}

Since the early 2000s, China and the USA were having fluctuations relationship. In 2003, the United States issued the National Strategy to Secure Cyberspace and related policy directives specifying key elements to secure computer-based systems, including government systems, and supporting critical infrastructure owned and operated by the private sectors (The White House, 2010:5). Based on its strategies and policies, The USA formed the Department of Homeland Security as an institution that protected the critical infrastructure (CIP) in cyberspace (Powner, 2009:3). In addition, the roles and responsibilities of this agency are:

1. Develop a comprehensive national plan related to CIP, including cybersecurity

2. Establish and enhance national cyber analysis, and threat preventive capabilities

3. Provide and coordinate the incident response and restoration plans

4. Identify, assess, and support efforts in reducing cyber threats and strengthening international cybersecurity (Powner, 2009:3-4).

Cybersecurity policy in the United States then became a substantial task for President Obama as President Bush's successor. In 2009, President Obama's administration reviewed the previous cyber policy titled Cyberspace Policy Review: Assuring a Trusted and Resilient Information and Communications Infrastructure (The White House, 2010:5). An action plan formed that focuses on protecting information and communication infrastructure, protecting the privacy of citizens, companies, and the state, developing the United States' position for an international cybersecurity policy framework, and strengthening international cooperation related to cybersecurity, as well as preparing a draft strategy in dealing with threats and cyber-attacks (The White House, 2010:6).

In 2011, the United States issued the International Strategy for Cyberspace which contained the United States strategy in strengthening international cooperation through diplomacy and cybersecurity defence from global cyber threats. There are several policy priorities such as, promote international markets transparency, protect, and enhance security, promote global governance in cybersecurity and support internet freedom and privacy protection. In this regard, the United States and China for the first time agreed to include cyber issues as an important agenda in bilateral relations ( $\mathrm{Xu}, 2011: 1)$.

However, the United States accused China of carrying out a series of espionage activities. Before the two countries entered cyber cooperation, the United States and China were involved in cyber conflicts in the Titan Rain and Shady RAT operations 
since 2003. Operation Titan Rain and Shady RAT were espionage operations conducted by China against the US government, such as the Department of Homeland Security and the United States Department of Defence and private institutions.

In addition, it was recorded from 2011 to 2013 after the cooperation between the two countries, China operated espionage activities against the United States Department of Defence, which was called The Operation Beebus. The United States also carried out espionage activities against a Chinese company namely Huawei called Operation Shot giant from 2010 to 2014 (Bebber, 2017:2).

The relationship between the two had worse due to statements by Edward Snowden, a former agent of the Central Intelligence Agency (CIA). He was also a former agent of the National Security Agency (NSA) of the United States. He stated about the existence of a mass internet surveillance program by the United States. He also explained the United States cyber espionage campaign against China and the United States has been spying on China's information technology, Banks, and Chinese Communist Party Leaders (Baezner, 2018:2). As a result of mutual accusations between the two countries, relations between those two have worsened. Moreover, distrust has dominated between the United States and China bilateral relations.

In 2015, President Obama and President Xi Jinping announced a common understanding. It was an understanding and agreement between the two countries not to carry out espionage activities, especially commercial and economic espionage that steals trade secret information and other important information. The results of the mutual understanding were forming an agreement called the 2015 US-China Agreement (Baezner, 2018:3).

In this case, as from the conflict between the United States and China then the two countries agreed to cooperate but then a conflict occurred until, in the end, the two countries agreed to sign an agreement related to cyber, this paper will analyse the motivation of the United States having cybersecurity agreement and cooperation with China.

\section{METHOD AND THEORETICAL REVIEW}

This research employs qualitative data analysis, in which the author refines and classifies the data so that it can support the answer to the research question; Cyber Security 
According to Myriam Dunn Cavelty in Cyber Security, a common problem in cyber threats is attacking information security regarding basic information security and systems (Cavelty, 2018:17). Therefore, information assurance is the main protection concept in cybersecurity.

\section{Information Assurance}

Information Assurance is the main concept in cybersecurity. Information security assurance is standard practice for risk management relating to the use, process, storage, and information or data transmission (Schou \& Trimmer, 2005). Protection of information is the most basic and important thing that must be done by the state in terms of maintaining cybersecurity.

Information assurance is rooted in risk analysis where the results of the risk analysis are used to guide in areas experiencing or having the highest risk, and based on this, plans and policies are developed to ensure that the system is fully protected.

This model of security assurance has three main objectives. The three objectives are Confidentiality refers to the protection of information from disclosure by unauthorized parties. Integrity refers to protecting information from being changed by unauthorized parties. And thirdly, Availability, which means that information must always be available in the authorized party requires the information (Schou \& Trimmer, 2005). In information security, the basic objective is the prevention of cyber-attacks by establishing strategies related to information security which are divided into two levels; namely the national level and the international level where each level also consists of several forms of strategy (Cavelty, 2012:17).

\section{Cyber Deterrence}

Cyber deterrence refers to a state's efforts to give concern to the enemy by showing the cyber capabilities of that country. Not only giving concern to the enemy but also showing actors in the international system about the capabilities and capacities of information and communication technology owned by the country.

According to W. Goodman, cyber deterrence is preventing attackers from taking aggressive actions in cyberspace (Stevens, 2012:151). Two strategic components implemented by the nation-state in terms of deterring the enemy are; deterrence by denial and deterrence by punishment or retaliation.

Deterrence by denial is preventing attackers from taking advantage derived from a cyber-attack that was launched. Deterrence by denial aims to decrease the advantage sought by attackers by increasing defensive measures to protect 
computer systems and networks (Stevens, 2012:151-152). Deterrence by punishment or retaliation is a deterrence strategy in the form of offensive actions and leads to the use of threats against attackers by imposing sanctions or penalties in the form of economic sanctions and retaliation or anything that results in the attackers receiving huge losses than the gains they earn from attack (Stevens, 2012:152).

\section{Cyber Offense and Defence}

Cyber offense contains a series of national strategies used to attack enemies such as launching DoDs attacks, Malware, sabotage, and so on to attack critical infrastructure and weaken enemy computer systems and networks as well as obtain information by conducting espionage activities. In addition, cyber offenses are carried out aimed at protecting computer systems and networks from enemy attacks. Cyber offenses that are commonly carried out in the military and in the country's national security strategy are to increase the capability of the offense. OCC itself is defined as a capability designed to achieve some achievements or goals related to a country's offensive actions against its targets (Smeets \& Lin, 2018:57). In addition, another form of offensive action is in the form of cyber deterrence by punishment as described previously.

Cyber defence refers to a state's efforts to improve its national defence by improving its cyber-defence system, upgrading the software system, finding faults, and repairing the damage to the system. Cyber defensive action focuses on prevention, detection, and rapid response to attacks or threats so that critical infrastructure and information security can be fully protected. In general, there are two forms of cyber defence. The first one is to implement cyber operations and improve the resilience system so that cyber defence stability can be maintained. The second is cyber defence by exchanging information and strengthening relations with the private sector, the state, international organizations.

\section{Critical Infrastructure Protection}

Since the 1990s, critical infrastructure has been the main object of reference in the cybersecurity debate. According to Presidential Policy Directive 21 (PPD-21), 16 main State Infrastructure sectors that must be protected are the Chemical Sector, Communications Sector, Dams Sector, Emergency Services Sector, Financial Services Sector, Government Facilities Sector, Information Technology Sector, Transportation Systems Sector, Water and Waste System Sectors, Nuclear Materials and Reactor Sector, Healthcare Sector, Food, and Agriculture Sector, Energy Sector, defence Industrial Base Sector, Manufacturing Sector, and Commercial Facilities Sector (Department of Homeland Security, 2019). 
The main challenges in protecting critical infrastructure come from the privatization and deregulation of large parts of the public sector in the 1980 s and the globalization process in the 1990s. There is a lot of the transfer of critical infrastructure into private hands. Therefore, the principles in protecting important infrastructure are the existence of Public-Private Partnerships and Information Sharing (Cavelty, 2012:19).

Public-Private Partnerships (PPP) are a form of cooperation between the state and the private sector in protecting the important infrastructure. The form of collaboration was to facilitate the exchange of information between companies and the government specifically for security. The existence of mutual benefit between the exchange of information was reflected in the benefits of the private sector in obtaining information by the state intelligence service and from the state sector obtaining more advanced technological knowledge.

\section{Cyber Norm Construction}

The design of defensive capabilities and the design of laws are undeniable (Cavelty, 2012:19). Many countries, international organizations, and other international communities are raising awareness by conducting international cooperation and agreeing on mutually agreed rules and norms. After the Stuxnet case, countries have begun to seek to control the exploitation of computer systems used for military purposes through arms control or the establishment of multilateral norms and international agreements (Cavelty, 2012:17). The formation of norms is intended to protect human rights and state sovereignty so that with these norms the state will be aware that the state must have limits in carrying out activities in cyberspace.

According to Finnemore, if strong norms processes, as done by constructing, promoting, and institutionalizing are an integral part of good cyber norms, then cyber norm advocates should devote as much attention to the process as they would have to negotiate in terms of achieving the desired goals (Finnermore \& Hollis, 2016:460). Based on this explanation, the concept of cybersecurity is summarized in the following chart 1.1 


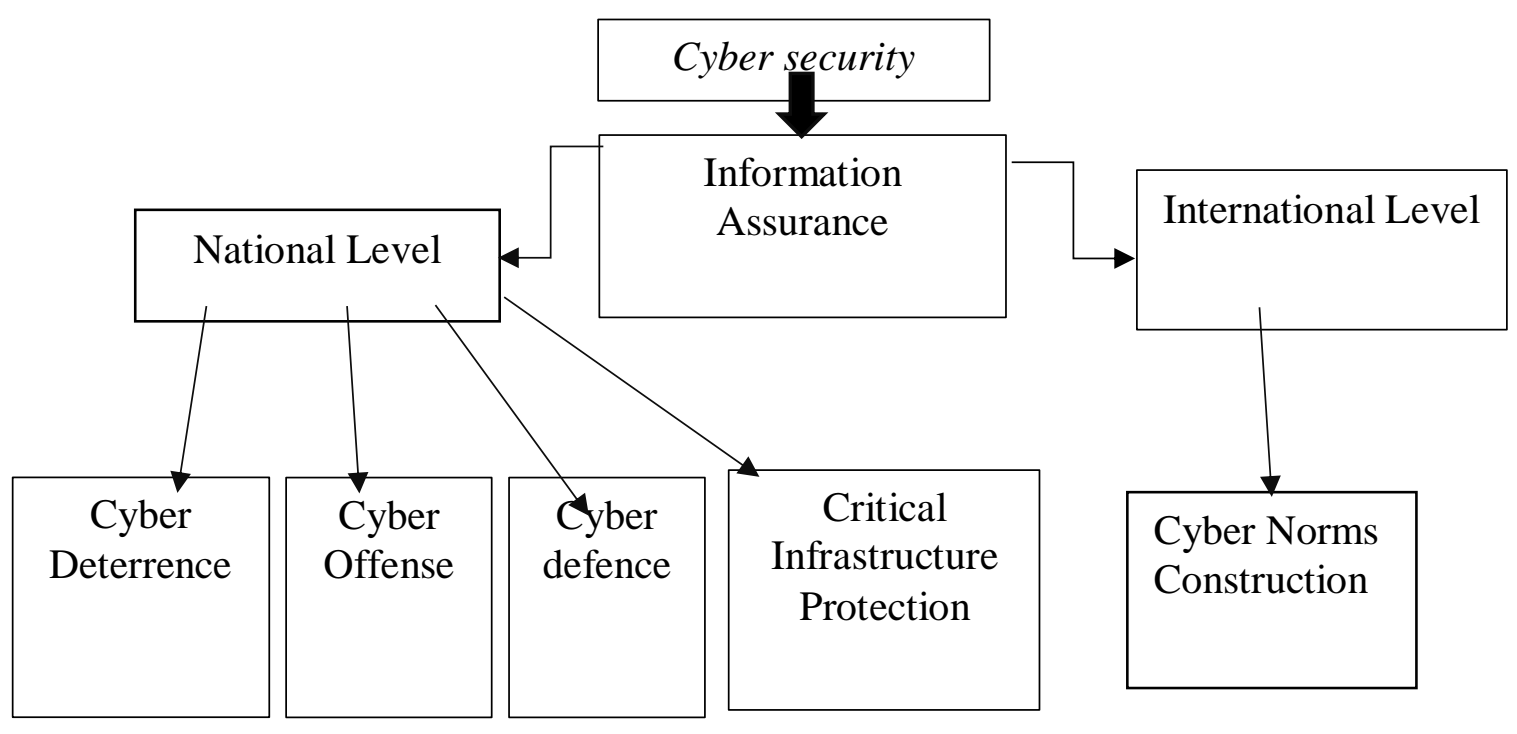

Chart 1. Conceptual Framework

Source: Myriam Dunn Cavelty, 2015

\section{RESULT AND DISCUSSION}

\section{Information Assurance}

This indicator used as the main indicator in analysing the assurance of information protection in cybersecurity. According to Myriam Dunn Cavelty, in her article entitled cybersecurity, information security is a top priority (Cavelty, 2012:17). The assurance of information owned by a country is seen from country's strategies and efforts in keeping their important information secret, both at the national and international levels. This is important because the information is a milestone in cybersecurity. If the enemies or hackers could break into state secret information, whether in the political, economic, military fields, or data in critical infrastructure, then a country's information system network becomes very vulnerable. In addition, this disrupts the stability of a country's cyber national security (Cavelty, 2012:118).

\section{National Level}

In this condition, the researcher analyses domestic strategies related to cybersecurity and sees whether there is a link between these strategies and the cybersecurity cooperation of the United States and China which was marked by the establishment of a cyber agreement in 2015. 


\section{Cyber Deterrence United States}

The United States reported their investigation of the Chinese Government and suspected irresponsible quasi-affiliated (combination between public and private organization) entities of accessing the United States Government and Private Sector databases for the purpose of economic espionage. Then in 2014, the United States Department of Justice indicted five hackers and was also a member of China's People's Liberation Army (PLA) with charges of computer hacking and economic espionage perpetrated against six American entities in the United States nuclear power, metals, and solar industries (Saalman, 2017:5). Regarding the case, China responded by suspending the activities of the China Cyber Working Group (The U.S.-China Cyber Working Group) which was formed in 2013 and threatening to suspend cooperation - other existing cooperation with the United States (Saalman, 2017:5).

This case indicates that the two countries use cyber deterrence by punishment strategies to respond to phenomena that occur between the two countries. Before the United States proposed cyber cooperation with China, President Barack Obama stated that all aggressive actions needed to be stopped and warned that the United States Government was preparing some countermeasures (Stevens, 2012:151).

According to Timothy M. McKenzie (2017:10-11), in his writing entitled "Is Cyber Deterrence Possible", the strategy in cyber defence to avoid enemies which are sponsored by the State, is not to use offensive strategies. Defensive strategies can be used to avoid war and if the attacked country has a large enough influence, then imposing sanctions in the form of economic sanctions and diplomatic channels is also a pretty good option.

From those facts, it can be concluded that the United States finally cooperated with China because the United States began to implement a cyber deterrence strategy against China. The United States did not take offensive action due to China's immediate response to suspending cooperation and took a more subtle approach but insisted that it would impose sanctions and threats if China violated the agreement.

\section{The United States Cyber Offense}

Improving the capability of offense is important in military operations related to national security. This also applies to the capability of cyber offense / Offensive Cyber Capabilities (OCC) (Smeets \& Lin, 2018:57). 
The term "Offensive Cyber Capabilities" itself has many meanings. OCC can be defined as a capability designed to access a computer system or network to harm an enemy or to obtain some achievement or goal related to the action (Smeets \& Lin, 2018:57-58). The OCC has a very broad form including cyber espionage, information warfare, and information operations.

Operation Shot giant is a cyber-attack operation carried out by the United States, precisely by the National Security Agency against China, which started from 2009 to 2013. United States NSA agents carried out cyber-attacks in the form of espionage against Chinese politicians and companies. One of the main targets in this operation is Huawei, a smartphone and tablet company that is also the secondlargest supplier of network equipment such as WLAN routers and fiber optic cables in the world (Spiegel, 2014). This operation was revealed to the public after Edward Snowden, who is a former NSA, issued statements and reports related to cyber activities carried out by America, one of which was against China (Price, 2014). The targets of the United States itself include Former Chinese President Hu Jintao, China's Ministry of Commerce, Banks, and Telecommunications Companies including Huawei (Sanger \& Perlroth, 2014).

A special unit within the US intelligence agency managed to infiltrate Huawei's network and copy over 1,400 customer lists and internal documents. NSA workers also managed to access not only archived e-mails but also the confidential source code of individual Huawei products (Segal, 2016:8). In addition, the United States also hacked into Huawei's headquarters network where all mail traffic from employees and even the CEO of the Company can be accessed there so that the NSA can read most of the E-mails sent by company workers since 2009 (Segal, 2016:8).

One of the objectives of this operation was to find links between Huawei and the People's Liberation Army. In addition, another objective is that the operation seeks to exploit Huawei technology. It is reported that the NSA aims to conduct surveillance over the computer network of telephones sold by Huawei Company to other countries (Sanger \& Perlroth, 2014). American officials themselves deny that the United States and the NSA are spying on foreign companies, including Huawei, to help American companies gain a competitive advantage (Bortz, 2014:1). The United States side confirmed that the activity is a data collection activity in preparation for imposing economic sanctions if the target is proven to have committed a crime or violator or takes the foreign policy of another country as a reference for taking action (Bortz, 2014:1). Even so, China condemned this operation and it made relations between the two countries even worse.

Although the OCC has a goal not only as deterrence or an attack on the enemy but as a form of defence for a country, the United States Cyber Offense against China 
does not indicate the United States motivation in conducting cyber cooperation with China because the form of this offensive itself is a form of conflict while Cooperation is the opposite of conflict.

\section{United States Cyber defence}

United States cyber defence can be seen from the strategies and initiatives issued by the Department of defence Strategy for Operating in Cyberspace. In 2011, the department issued five strategic initiatives (Five Strategic Initiatives), and related to this research, only Strategic Initiative 5 will be explained in more detail (U.S. Department of Defense, 2011:6).

\section{Strategic Initiative 5}

The Department of defence will build and strengthen relationships and alliances with the United States and international partners to strengthen collective cybersecurity. Regarding the involvement of the Department of defence in the international system, the Department of defence also supports the United States' policy regarding cyberspace, namely The U.S. International Strategy for Cyberspace. In addition, the Department of defence also supports the president's commitment to freedom, privacy, and free flow of information. In addition, the Department of defence also assists the efforts of the United States government in advancing development and promoting cyber-related norms and principles that generally include the promotion of openness, resilience, security, and reliability (U.S. Department of Defense, 2011:7).

Then in 2015, related to cybersecurity defence, with the aim of protecting the State and the interests of the United States from attacks including cyber-attacks, the Department of defence then formed "The DoD Cyber Strategy". Related to this research, what will be explained in more detail is strategic goal $\mathrm{V}$ which will be explained in more detail as follows.

\section{Strategic Goal V}

The fifth strategy is to build and maintain international alliances and partners to be able to identify common threats and enhance international security and stability. The mission of the Department of defence requires close collaboration with allies and international partners. The height of the threat, as well as the breadth of networks and systems, compel the Department of defence to make options and focus its partnership capacity initiatives in areas that are crucial to the interests and security of the United States (Department of Defense, 2015:17). 
The United States cybersecurity defence strategy was issued by the United States Department of defence in 2011 and 2015. In both strategies issued, the Department of defence generally issued five initiatives and objectives in cyber defence strategy. Based on the explanations above, the United States' cyber defence strategy does not only focus on domestic affairs but also the initiation of strategies in the form of development and strengthening of international cooperation related to cybersecurity.

In addition, strategy goal number five in the United States cyber defence strategy in 2015 states that the United States focuses on international involvement in the Middle East, Asia Pacific, and Important Allies in NATO (Department of Defense, 2015). Based on this statement, China is one of the countries from these regions which is the focus of the United States in international engagement. This is because China is one of the countries in the Asia Pacific region, and in the same year the United States and China agreed to cooperate on cyber.

The United States and China initiated cybersecurity cooperation and produced an agreement called the U.S.-China cyber agreement in 2015. In the agreement, the two countries agreed not to carry out or support espionage activities, especially in terms of economic espionage. In addition, there are seven points of cyber cooperation between the two countries.

Against cyber-attacks that occurred from 2003 to 2014, the United States used a defensive strategy with a more subtle approach to the enemy. After the cyber cooperation agreement between the United States and China in 2015, cases of cyber-attacks in the United States decreased by $90 \%$ and the two countries also agreed to continue to hold meetings every six months (Louie, 2017).

Based on these data, it is indicated that related to the vulnerability of the United States information system which is characterized by many cyber-attack operations that attack and target important United States information, information risk management in information assurance at the national level, the United States prefers a defensive strategy by cooperating rather than strategic offensive. The offensive actions taken by the United States previously had a bad effect on bilateral relations between the two countries. On the other hand, with cooperation, cyberattacks against the United States decreased by $90 \%$ after the cooperation and this also affects the role of the two countries in terms of realizing international cybersecurity. 


\section{Critical Infrastructure Protection}

In 2013, President Obama issued "executive order 13636" which contains the government's efforts to direct cybersecurity regulations throughout the public and private sectors to improve cybersecurity defence capabilities that are stronger (Fisher et. al., 2013:5-6). The main objective of Executive Order 13636 (EO 13636) is to improve cybersecurity in critical infrastructure, due to the increasing number of cyber threats and attacks that threaten national security (Fisher et. al., 2013:1).

In addition to EO 13636, The Presidential Policy Directive-21 (PPD-21) document was also released in 2013 and has the same goal of protecting critical infrastructure from cyber threats and attacks. Similar to the requirements in EO13636, PPD-21 also requires collaboration between the government and the private sector engaged in the security of critical infrastructure, to manage risk and improve defence in the face of all threats (The White House, 2019). PPD-21 also establishes and identifies 16 separate critical infrastructure sectors including the financial services sector. The difference between EO 13636 and PPD-21 is, EO 13636 focuses exclusively on cyberrelated threats, while PPD-21 focuses on identifying all threats and hazards to the security and resilience of critical infrastructure which then forms the National Infrastructure Protection Plan (NIPP) (The White House, 2019).

DHS describes collaboration between the public and private sectors as a condition in which government agencies interact directly with private companies. The relationship between the two includes the exchange of information about resources, risks, losses, and service offerings. In the era of globalization where the development of advanced technological innovation today, not only results in competition in increasing technological innovation both between countries and between the state and the private sector but also the existence of interdependence.

This interdependence is based on the existence of various attacks and threats, especially cyber-attacks and threats which of course require the development of qualified technology to be able to maintain security, especially in the security of information and important infrastructure. However, in relation to this indicator, there is no indication that the motivation of the United States to conduct cybersecurity cooperation with China is based on strengthening cooperation between the public and private sectors, because the United States is associated with strengthening partners with the private sector more inclined to private parties originating from America. Union. This is because the main goal in establishing partners with the private sector is to protect the country's important infrastructure and avoid threats from within and from outside. 


\section{International Level}

\section{Cyber Norm Construction}

On the indicators of the formation of cyber norms, to determine the influence of the formation of cyber norms as a motivation for the United States to carry out cyber cooperation with China. Norms, in International Relations, are shared expectations, values, and principles about appropriate and inappropriate behaviour in the international community.

The United States and China have different perspectives in defining the cyber world. In general, the United States holds the view that every citizen has the right to be in the cyber world and carry out any activities, and the United States has the principle of "Open, Safe, and Secure" in relation to the cyber world. Meanwhile, China believes that the state has an obligation to control traffic and everything in the cyber world (Harold et. al., 2016:2).

In Finnemore's thesis, Constructing Norms for Global Cybersecurity, it is stated that the success of bilateral cyber norms can result in "copying", especially when the country involved has a high status. In addition, bilateral cyber norms can also affect multinational institutions, especially in the cyber field, and further strengthen the influence of a country in the international system (Finnermore \& Hollis, 2016:460).

Regarding the cyber confrontation between the United States and China, the United States then took the path of cooperation and turned to cyber norms to overcome the discomfort in the cyber world and overcome the cyberattacks that continue to occur, especially those allegedly originating from China (Hollis, 2016). In relation to these cyber norms, the United States has set important goals (Hollis, 2016:3).

a. Reducing the theft of important data and information belonging to the United States through cyber means

b. Reducing the risk of unintentional and unwanted armed conflict due to expectations that are not aligned with phenomena in the cyber world.

Bilateral cyber norms set by the two countries, namely the United States and China through the 2015 cyber agreement regarding norms that prohibit commercial cyber espionage, give mimicry effects to other countries as evidenced by the similar cyber cooperation between Britain and China, and Germany and China in October 2015, exactly one month after the cyber agreement between the United States and China (Finnermore \& Hollis, 2016:465). 
Regarding the formation of international cyber norms, in 2013 there was an initiation at the United Nations session by Russia which sponsored a resolution to establish The Working Group of the General Assembly which was open to studying the norms contained in the reports of the United Nations Group of Governmental Experts (The United Nations Group of Governmental Experts). UN GGE) earlier, identified new norms, and studied the possibility of "building regular institutional dialogue under the auspices of the UN" (Maurer \& Taylor, 2018). Another resolution by the United States, sponsoring the resolution, is to establish The New of Governmental Experts to study information security and how international law applies to state actions in cyberspace and identify ways to promote compliance with cyber norms (Maurer \& Taylor, 2018).

Then in December 2015, The UN General Assembly agreed to adopt a resolution proposed by the United States regarding the formation of a New Group of Governmental Experts to study information security with a view to promoting norms, rules, and principles of responsible behaviour by states (Nicola, 2015). In addition, the G2O countries also agreed to apply the norms of criticism against commercial cyber espionage.

Previously, UN GGE itself was a government expert group under the auspices of the United Nations which was formed in 2004 which focused on development in the field of information and telecommunications in the context of international security. Two major achievements of the UN GGE that must continue to be fulfilled are outlines the global cybersecurity agenda and introduces the principle that international law applies to the digital space (Digital Watch, 2019).

In accordance with the US cyber defence strategy and international policies related to cybersecurity, the United States is more focused on strengthening international cooperation by establishing common norms related to international cybersecurity. After the cyber cooperation between the United States and China in 2015, it gave a positive signal at the international level. The reason is, this proves that diplomatic solutions can be used to solve cybersecurity issues ${ }^{1}$. This agreement between the United States and China can be considered as the first step towards the internationalization of cybersecurity norms and provides a domino effect for other countries that initially engage in confrontation and then turn to cooperation related to cybersecurity.

In addition, based on the explanation above, another reason for the United States to conduct cybersecurity cooperation with China at the international level is so that

\footnotetext{
${ }^{1}$ Marie Baezner,"Cybersecurity in Sino-American Relations”, CSS Analyses in Security Policy, No.224, 2018
} 
the resolutions proposed by the United States and bilateral cyber norms between the United States and China can be accepted and affect the international system so that the United States' role in cybersecurity international is getting stronger.

\section{CONCLUSION}

The results of the analysis found that at the national level, the United States' cyber defense strategy affected cybersecurity cooperation with China after the offensive strategy was less effective for bilateral relations between the two countries. This is evidenced by the significant reduction in cyberattacks in the United States, reaching 90\% after the cyber agreement between the two countries in 2015. Meanwhile, at the international level, the construction of bilateral norms between the United States and China regarding cyber espionage affects the international system and other countries have also begun to apply normative and diplomatic approaches to cybersecurity issues. This is in line with the United States' foreign policy goals related to cybersecurity.

\section{REFERENCES}

Baezner, Marie."Cybersecurity in Sino-American Relations". CSS Analyses in Security Policy. No.224. (2018)

Bebber, Robert ."China's Cyber Economic Warfare Threatens U.S”.US Naval Institute. Vol.143. No. 7. (2017)

Bortz, Travis. "Cyberspace: United States vs China”. The Journal of Hgh Technology Law. https://sites.suffolk.edu/jhtl/2014/04/04/cyberspace-united-statesv-china/ (diakses 15 Maret 2019)

Dunn Cavelty, Myriam. Cyber Security. Oxford:Oxford University Press.(2012)

Finnermore, Martha. dan Duncan B. Hollis. "Constructing Norms for Global Cybersecurity". The American Journal of International Law. Vol.110. No.3 (2016)

Fisher, Eric A. dkk., "The 2013 Cyber security Executive Order: Overview and Considerations for Congress". Congressional Research Service. (2013) http://www2.gwu.edu/ nsarchiv/ NSAEBB/NSAEB B424/docs/Cyber089.pdf.

Hollis, Duncan B. "China and the US Strategic Construction of Cybernorms: The Process is the Product". Aegis Paper Series.No.1704 
Lewis, James A."Computer Espionage, Titan Rain and China".Center for Strategic and International Studies-Technology and Public Policy Program, http://cybercampaigns.net/wp-content/uploads/2013/05/Titan-RainMoonlight-Maze.pdf (diakses 6 Maret 2019)

Louie, Celia. "U.S-China Cybersecurity Cooperation". The Henry M. Jackson School of International Studies.(2017). https://jsis. washington.edu/news/u-schina-cybersecurity-cooperation/ (diakses 23 April 2019)

Maurer, Tim dan Kathryn Taylor. "Outlook on International Cyber Norms: Three Avenues For Future Progress". Carneige Endowment for International Peace.2018. https://carnegie endowment.org/2018/o3/o2/outlook-oninternational-cyber-norms-three-avenues-for-future-progress-pub-75704 (diakses 17 April 2019)

McKenzie, Timothy M. "Is Cyber Deterrence Possible”. Air Force Research Instituse Papers (2017)

Nicola, Stefan. "China Working to Halt Commercial Cyberwar in Deal with Germany", BLOOMBERG (2015) https://www.bloomberg.com/news /articles/2015-10-29/china-working-to-halt-commercial-cyberwar-in-dealwith-germany (diakses, 29 April 2019)

Powner, David. "National Cybersecurity Strategy: Key Improvements Are Needed to Strengthen the Nation's Posture".United States Government Accountability Office.2009

Presidential Document. "Excecutive Order 13694: Blocking the Property of Certain Person Engaging in Significant Malicious Cyber-Enabled Activities”. Federal Register. Vol. 80. No. 63 (2015)

Ryan, Camille dan Jamie M. Lewis. "Computer and Internet Use in the United States : 2015”. American Community Survey Reports. 2017. diakses di https://www.census.gov/content/dam/Census/library /publications/2017/acs/acs-37.pdf, 18 Desember 2018

Saalman, Lora .Rethinking China-Russia-U.S. Deterrence in Cyberspace”.ThinkChina.dk Policy Brief. No.4 (2017)

Sanger David E. dan Nicole Perlroth."NSA Breached Chinese Servers Seen as Security Threat".New York Times, https://www.nytimes.com/2014/03/23 /world/asia/nsa-breached-chinese-servers-seen-as-spy-peril.html. (diakses 12 maret 2019)

Schou, Corey D. dan Kenneth J. Trimmer. "Information Assurance and Security". Journal of Organizational and End User Computing on Information Security (2005).https://www.researchgate.net/publication/220349069 Information Assurance and Security 
Smeets, Max. dan Herbert S. Lin. "Offensive Cyber Capabilities: To What End" NATO CCDCOE (2018)

Stevens, T. "A cyberwar of ideas?: Deterrence and norms in cyberspace". Contemporary Security Policy. Vol. 33. No.1. (2012): 151. doi:10.1080/13523260.2012.659597

The White House. "Critical Foundations: Protecting America's Infrastructure"(1997) https://fas.org/sgp /library/pccip.pdf, diakses 7 April 2019

The White House. "Presidential Decision Directive/NSC-63"(1998) https://nsarchive2.gwu.edu /NSAEBB/NSAEBB424/docs/Cyber-012.pdf (diakses 7 April 2019)

The White House, "National Plan for Information Systems Protection Version 1.0", 2000, https://fas.org/irp/offdocs/pdd/CIP-plan.pdf, diakses (7 April 2019)

The White House."The National Strategy to Secure Cyberspace".2003. https://www.energy.gov/sites/prod/files /National\%20Strategy\%20to\% 20Secure\%20Cyberspace.pdf. (diakses 1 April 2019)

The White House. "Presidential Policy Directive/PPD-21: Critical Infrastructure Security and Resilience," U.S. General Services Administration. http://www.gsa.gov/portal/ mediaId/176571/fileName/ATTCH_2_-_PPD21.action (diakses 19 April 2019)

The White House Office of the Press Secretary. "The U.S-China Strategic and Economic Dialogue". 2009. https://obamawhitehouse.archives.gov /realitycheck /the-press-office/remarks-president-uschina-strategic-andeconomic-dialogue. (diakses 27 Maret 2019)

The White House Office of the Press Secretary. "U.S-China Joint Statement".2011. https://obamawhitehouse.archives.gov/the-press-office/2011/01/19/uschina-joint-statement. (diakses 27 Maret 2019)

The White House. "The National Strategy to Secure Cyberspace”. Washington. 2003. diakses di https://georgewbush-whitehouse.archives.gov/pcipb/ (diakses 18 Desember 2018)

The White House. "Cyberspace Policy Review : Assuring a Trusted and Resilient Information and Communication Infrastructure". 2010 diakses di http://www.whitehouse.gov/assets/documents /Cyberspace_Policy_Review_final.pdf

U.S Department of Defense."Department of Defense Strategy for Operating in Cyberspace" (2011) 

- JISEA Purwanti | The United States Motivation in Having Cyber Security

Warren Harold, Scott, Martin C. Libicki. Astrid Stuth Cevallos. "Getting Yes With China in Cyberspace”. ( Santa Monica. CA: RAND Corporation.2016)

$\mathrm{Xu}$, Ting. "China and The United States : Hacking Away at Cyber Warfare". Asia Pacific Bulletin. No. 135. 2011

Yeniman Yildirim, Erbu ."The Importance of Risk Management in Information Security”. IIER International Conference. ISBN: 978-93-86083-34-0 (2016) 